\title{
Polymer-supported L-prolinol-based catalysts for the enantioselective addition of dialkylzinc reagents to $N$-(diphenylphosphinyl)imines
}

\author{
Raquel Almansa, Juan F. Collados, David Guijarro* and Miguel Yus* \\ Departamento de Química Orgánica, Facultad de Ciencias and Instituto de Síntesis Orgánica (ISO), Universidad de Alicante, \\ Apdo. 99, 03080 Alicante (Spain).
}

Dedicated to the memory of Professor Balbino Mancheño Magán

\begin{abstract}
L-Prolinol-based ligands anchored to Merrifield or Wang-type resins have shown to form efficient catalysts for the enantioselective addition of dialkylzinc reagents to $N$-(diphenylphosphinyl)imines. The enantioselectivity achieved with the polymeric catalyst (ee up to $88 \%$ ) is slightly lower than the one obtained with the homogeneous ligand $N$-benzyl-L-prolinol, but the polymersupported ligand presents the advantage of its recyclability: it can be recovered and used in up to six consecutive catalytic cycles with only a slight detriment in the enantiomeric excess. The phosphinamides obtained as addition products can be transformed into the corresponding optically enriched $\alpha$-branched primary amines under mild acidic conditions.
\end{abstract}

\section{Introduction}

The enantioselective addition of dialkylzinc reagents to $N$-(diphenylphosphinyl)imines is one of the most reliable methods for the asymmetric synthesis of amines. ${ }^{1,2}$ The chiral phosphinamides that are obtained as addition products are easily transformed into the corresponding primary amines by a simple acidic treatment without any loss of optical purity. ${ }^{3}$ Dialkylzinc reagents ${ }^{4}$ are very interesting nucleophiles since they tolerate several functional groups, ${ }^{5}$ allowing the preparation of polyfunctionalised organic compounds. However, the reaction of $N$-phosphinylimines with dialkylzincs is very slow and low yields of the addition products are obtained in long reaction times unless an additive is used to facilitate the reaction. ${ }^{6-12} \beta$-Aminoalcohols are among the most efficient promoters for these addition reactions. A variety of them have shown to induce excellent enantioselectivities, but, in most cases, the use of a stoichiometric amount of the aminoalcohol ligand was necessary. ${ }^{6}$ A few years ago, we found out that $N$-benzyl-L-prolinol was a very efficient ligand for the addition of dialkylzinc reagents to $N$-(diphenylphosphinyl)imines, obtaining ee's up to $94 \%$ with 0.5 equivalents of the aminoalcohol. ${ }^{13}$ However, the amount of ligand utilized was still relatively high and we thought that the productivity of the catalyst could be increased if it could be easily recovered and reused several times. Moreover, the reuse of the catalyst would reduce the waste material and make the process more environmentally friendly, with potential applications in the chemical industry. One interesting way to achieve the recovery of the catalyst is the use of ligands immobilized on solid supports. There are several examples in the literature of addition reactions of dialkylzinc reagents to aldehydes ${ }^{14}$ and imines ${ }^{6 b, 15}$ promoted by supported aminoalcohols. The most popular supports that have been used are polymers, ${ }^{14,15 a, b, d}$ although some other supports have proved to be efficient, such as dendrimers, ${ }^{14 c-e, 15 c, e-g}$ silica gel, ${ }^{14 c-e}$ molecular sieves ${ }^{14 c}$ and zirconium phosphates. ${ }^{14 \mathrm{~d}}$ The immobilization of the chiral ligand onto an insoluble polymeric chain, such as polystyrene, is still one of the best options, since it allows the recovery of the ligand by a simple filtration. Continuing with our studies on the addition of dialkylzinc reagents to $N$-(diphenylphosphinyl)imines, we have developed L-prolinol-based ligands anchored to Merrifield or Wang-type resins and herein we report the results of our research activities.

\section{Results and discussion}

Keywords: $N$-(diphenylphosphinyl)imine; dialkylzinc; L-prolinol; polymer supported ligand; enantioselective addition.

*Corresponding author. Fax: +34-965903549; e-mails: dguijarro@ua.es, yus@ua.es 
Since $N$-benzyl-L-prolinol has shown to efficiently catalyse the addition of dialkylzincs to $N$ (diphenylphosphinyl)imines, ${ }^{13}$ we decided to prepare several polymers bearing the prolinol framework bonded to the polymeric chain through the benzylic substituent on the nitrogen atom. The supported aminoalcohols were synthesized from L-prolinol and commercially available Merrifield or Wang-type resins, both containing benzylic halide moieties that could be used as electrophiles to benzylate the nitrogen atom of L-prolinol. The commercial polymers and L-prolinol were stirred in DMF at room temperature for $90 \mathrm{~h}$ (Scheme 1). By using Merrifield resins with different chloride contents and changing the aminoalcohol load, polymers 1a-f with different levels of prolinol incorporation were obtained (Table 1, entries 1-6). In order to study the effect on the enantioselectivity of the presence of a linker separating the polymeric chain from the prolinol moiety, Wangtype resin 1g was also prepared (Table 1, entry 7). In all cases, the amount of aminoalcohol present in the polymeric ligands was calculated by determining the nitrogen content of the polymers by elemental analysis.

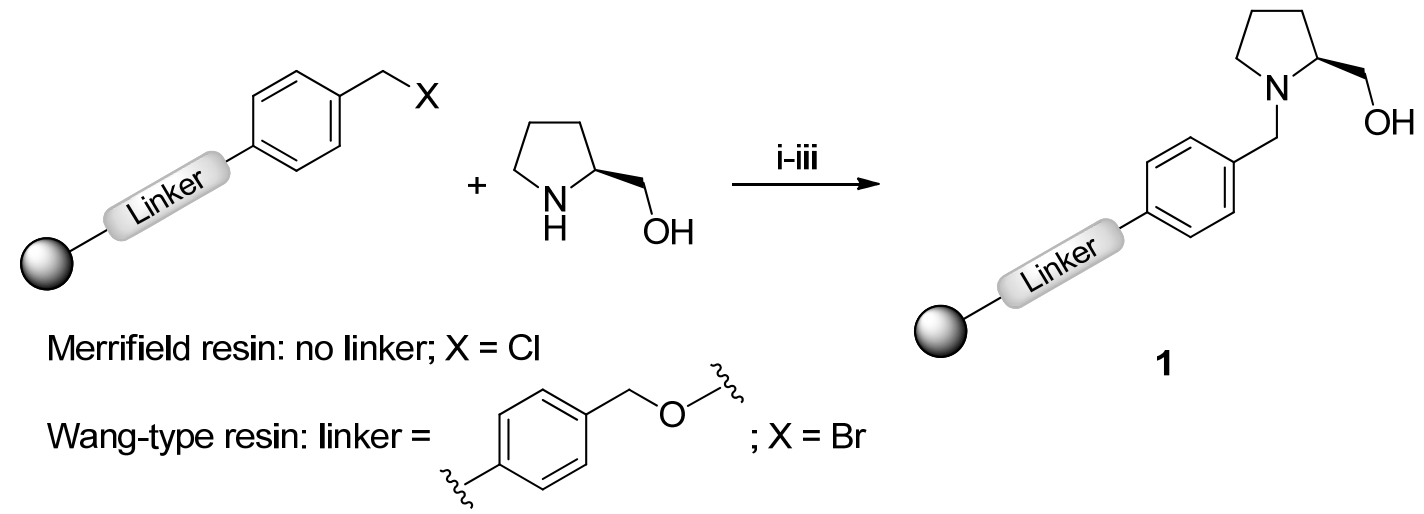

Scheme 1. Reagents and conditions: (i) DMF, $25{ }^{\circ} \mathrm{C}$, 90 h; (ii) Filtration; (iii) Successive washing with DMF, EtOH, THF, THF: $\mathrm{H}_{2} \mathrm{O}(1: 1), \mathrm{MeOH}$, acetone and $\mathrm{Et}_{2} \mathrm{O}$.

Table 1. Preparation of the polymer-supported prolinols

\begin{tabular}{|c|c|c|c|c|c|}
\hline \multirow[b]{2}{*}{ Entry } & \multicolumn{3}{|c|}{ Commercial resin } & \multicolumn{2}{|c|}{ Polymeric ligand } \\
\hline & Linker & $\mathrm{X}$ & $\mathrm{mmol} \mathrm{X/g}$ & No. & $\mathrm{mmol}$ prolinol $/ \mathrm{g}^{\mathrm{a}}$ \\
\hline 1 & --- & $\mathrm{Cl}$ & 1.0 & $1 \mathbf{a}$ & 0.61 \\
\hline 2 & --- & $\mathrm{Cl}$ & 4.3 & $1 \mathbf{b}$ & 0.87 \\
\hline 3 & --- & $\mathrm{Cl}$ & 1.5 & 1c & 0.93 \\
\hline 4 & --- & $\mathrm{Cl}$ & 1.5 & 1d & 1.09 \\
\hline 5 & --- & $\mathrm{Cl}$ & 1.7 & 1e & 1.48 \\
\hline 6 & --- & $\mathrm{Cl}$ & 4.3 & 1f & 3.10 \\
\hline 7 & & $\mathrm{Br}$ & $0.5-1.5$ & $1 g$ & 1.00 \\
\hline
\end{tabular}

${ }^{a}$ Determined by elemental analysis of nitrogen.

The polymeric ligands 1 were evaluated as promoters of the addition of diethylzinc to $N$ (diphenylphosphinyl)benzaldimine 2a as a model reaction (Scheme 2) and the results were compared with the one previously obtained by us with $N$-benzyl-L-prolinol as an homogeneous ligand. ${ }^{13}$ Diethylzinc (6 equiv) was added dropwise to a suspension of the polymeric ligand $\mathbf{1}$ (1 equiv) in the solution of the imine 2a in toluene at room temperature during ca. 10 min. After stirring for 2 days at the same temperature, the liquid phase was 
separated from the polymer by syringe and the solution was hydrolysed, affording, after work-up, the expected phosphinamide 3aa in the yields and ee's indicated in Table 2.<smiles>CC#CCCCC</smiles>

$2 a$<smiles>CCC(NP(=O)(c1ccccc1)c1ccccc1)c1ccccc1</smiles>

3aa

Scheme 2. Reagents and conditions: (i) polymeric ligand 1 (1 equiv), toluene, $25{ }^{\circ} \mathrm{C}, 2$ days; (ii) Separation; (iii) $\mathrm{NH}_{4} \mathrm{Cl}$ (aq.).

Table 2. Enantioselective addition of diethylzinc to imine $2 \mathbf{a}$ in the presence of supported prolinols $\mathbf{1}^{\mathrm{a}}$

\begin{tabular}{|c|c|c|c|}
\hline \multirow[b]{2}{*}{ Entry } & \multirow[b]{2}{*}{ Ligand } & \multicolumn{2}{|c|}{ Product 3a } \\
\hline & & Yield $^{\mathrm{b}}(\%)$ & $e^{c}(\%)$ \\
\hline $1^{\mathrm{d}}$ & $N$-benzyl-L-prolinol & 79 & 92 \\
\hline 2 & $1 \mathbf{a}$ & 84 & 82 \\
\hline 3 & $1 b$ & 71 & 84 \\
\hline 4 & 1c & 72 & 52 \\
\hline 5 & 1d & 84 & 62 \\
\hline 6 & $1 e$ & 78 & 74 \\
\hline 7 & 1f & 62 & 50 \\
\hline 8 & $1 g$ & 80 & 70 \\
\hline \multicolumn{4}{|c|}{$\begin{array}{l}\text { a All reactions were performed by dropwise addition of diethylzinc ( } 6 \text { equiv) over ca. } 10 \\
\text { min to a stirred suspension of the polymeric ligand } \mathbf{1} \text { ( } 1 \text { equiv) in the solution of imine } 2 \text { a } \\
(0.25 \mathrm{mmol}) \text { in anhydrous toluene }(3.5 \mathrm{~mL} \text { ) under argon at room temperature and stirring } \\
\text { was continued for } 2 \text { days. } \\
\text { b Isolated yield after column chromatography (silica gel, hexane/ethyl acetate) based on the } \\
\text { starting imine 2a. Isolated compound 3aa was always } \geq 95 \% \text { pure }\left(300 \mathrm{MHz}{ }^{1} \mathrm{H} \text { NMR). }\right. \\
\text { c Enantiomeric excess determined by HPLC using a ChiralCel OD-H column. The }(R)- \\
\text { enantiomer was the major one in all cases. } \\
\text { d }\end{array}$} \\
\hline
\end{tabular}

It was gratifying to see that polymeric ligands $\mathbf{1 a}$ and $\mathbf{1 b}$ gave ee's slightly lower than the one obtained with the homogeneous ligand (compare entries 1-3 in Table 2). However, the enantioselectivity decreased with the rest of the ligands derived from Merrifield resins, 1c-f (Table 2, entries 4-7). According to these results, it seems that a low prolinol incorporation in the polymeric catalyst leads to higher enantioselectivities. Ligand 1g, derived from a Wang-type resin, gave an ee of $70 \%$, which was only slightly higher than the one achieved with the Merrifield-type ligand 1d having a similar prolinol content (compare entries 5 and 8 in Table 2). Therefore, it seems that the possible beneficial effect of having a linker between the polymeric support and the prolinol moiety is not very pronounced in this case.

Next, we performed a recyclability study with the two ligands that gave the highest enantioselectivities, 1a and 1b. When the addition reaction of diethylzinc to imine 2a was complete, stirring was stopped, the polymer was 
allowed to settle at the bottom of the flask and the liquid layer was separated with the aid of a syringe. The polymeric ligand was then washed three times with anhydrous toluene under argon and it was directly used as promoter of the next addition reaction. The results obtained with both ligands in the different cycles are collected in Table 3 and represented in Figure 1. In all reactions, a small amount of a by-product resulting from reduction of the imine 2a was also observed, but it could be separated from the desired addition product by column chromatography. We assume that the reduction process took place via a $\beta$-hydride transfer from diethylzinc to the iminic carbon atom.

Table 3. Recyclability study performed with ligands $\mathbf{1 a}$ and $\mathbf{1 b}$. Yields and ee's obtained for the addition of diethylzinc to imine $\mathbf{2} \mathbf{a}^{\mathrm{a}}$

\begin{tabular}{cccccc}
\hline & \multicolumn{2}{c}{ Ligand 1a } & & \multicolumn{2}{c}{ Ligand 1b } \\
\cline { 2 - 3 } \cline { 5 - 6 } Cycle & Yield $^{\mathrm{b}}(\%)$ & $\mathrm{ee}^{\mathrm{c}}(\%)$ & & Yield $^{\mathrm{b}}(\%)$ & $\mathrm{ee}^{\mathrm{c}}(\%)$ \\
\hline 1 & 77 & 80 & & 60 & 84 \\
2 & 74 & 78 & & 67 & 72 \\
3 & 74 & 78 & & 58 & 50 \\
4 & 73 & 78 & & 66 & 52 \\
5 & 68 & 76 & & 68 & 46 \\
6 & 74 & 70 & & 58 & 38 \\
7 & 61 & 56 & --- & --- \\
8 & 68 & 50 & --- & --- \\
9 & 74 & 42 & --- & -- \\
\hline
\end{tabular}

${ }^{a}$ All reactions were performed by dropwise addition of diethylzinc (6 equiv) over ca. $10 \mathrm{~min}$ to a stirred suspension of the polymeric ligand 1 (1 equiv) in the solution of imine $2 \mathbf{a}(0.25 \mathrm{mmol})$ in anhydrous toluene $(3.5 \mathrm{~mL})$ under argon at room temperature and stirring was continued for 2 days. After completion of the reaction, the polymeric ligand was separated from the liquid layer, washed three times with anhydrous toluene and directly used in the next cycle.

${ }^{\mathrm{b}}$ Isolated yield after column chromatography (silica gel, hexane/ethyl acetate) based on the starting imine 2a. Isolated compound 3aa was always $\geq 95 \%$ pure (300 MHz ${ }^{1} \mathrm{H}$ NMR).

${ }^{c}$ Enantiomeric excess determined by HPLC using a ChiralCel OD-H column. The $(R)$-enantiomer was the major one in all cases. 


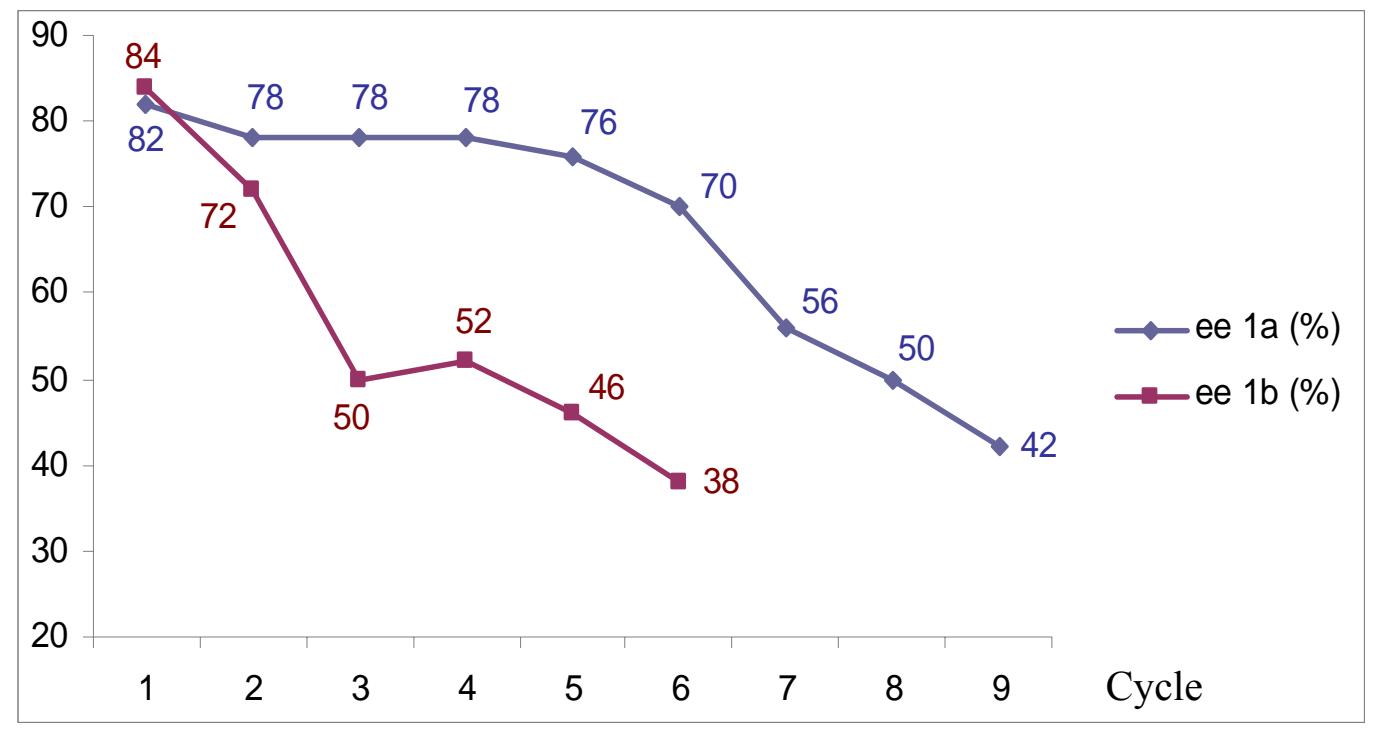

Figure 1. Enantiomeric excesses obtained in the addition of diethylzinc to imine 2a promoted by recovered ligands $\mathbf{1 a}$ and $\mathbf{1 b}$.

Both ligands gave yields in the range $60-80 \%$ in all the cycles. However, ligand 1a showed a much better recyclability than ligand $\mathbf{1 b}$. As it can be seen in Figure 1, the ee obtained with ligand $\mathbf{1 b}$ considerably dropped in the third cycle, whereas, in the case of the reactions promoted by ligand 1a, the ee value remained practically constant during the first five cycles, slightly decreased in the sixth cycle and started to fall down from the seventh cycle. The decrease in catalytic activity of these ligands with the number of cycles could be due to a degradation of the polymeric chain after prolonged stirring. ${ }^{14 \mathrm{c}}$ Although a stoichiometric amount of the polymeric ligand 1a was used, the fact that it could be quantitatively recovered by a simple separation procedure and reused in five more cycles without significant loss of chiral induction improves its catalytic efficiency.

Once we had established that 1a was the ligand of choice, we decided to investigate the scope of this reaction by testing some other dialkylzinc reagents and imines (Scheme 3 and Table 4). As stated above, the addition of diethylzinc to imine 2a gave product 3aa in $83 \%$ yield and $80 \%$ ee (Table 4, entry 1 ). With the idea of reducing the reaction time and increasing the yield, this reaction was repeated by heating in a microwave reactor at $50{ }^{\circ} \mathrm{C}$ (70 W, 0.8 bar) for $1 \mathrm{~h},{ }^{16}$ which improved the yield to $95 \%$, but caused a detriment of the ee to $62 \%$ (Table 4 , entry 2). As previously reported, ${ }^{3,6 \mathrm{c}}$ dimethylzinc turned out to be much less reactive than diethylzinc and no addition product was formed after stirring the reaction for 2 days at room temperature. The addition of diisopropylzinc to imine 2a gave product 3ab in good yield and enantioselectivity (Table 4, entry 4). Dibutylzinc was as efficient as diethylzinc, affording the addition product 3ac in $80 \%$ yield and $86 \%$ ee (Table 4, entry 6). We also tried to prepare compounds 3aa-ac by reaction of the corresponding dialkylzinc reagent with the sulfinic acid adduct $\mathbf{4 a}$ (Scheme 3 ). In these reactions, imine 2a is generated in situ and then undergoes the addition of the dialkylzinc reagent. ${ }^{17}$ This procedure gave slightly higher yields for all products 3aa-ac. However, variable results were obtained concerning the enantioselectivity: a small improvement was observed for the ethylation product 3aa, whereas lower ee's were obtained for compounds 3ab-ac (compare entry 1 with 3 , entry 4 with 5 and entry 6 with 7 in Table 4). 


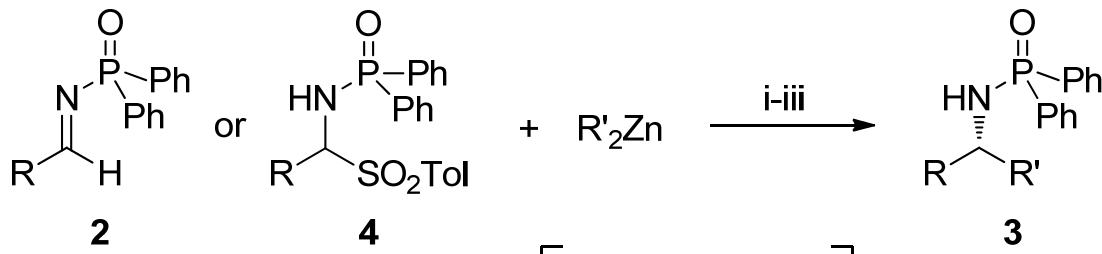

$$
\left.\begin{array}{l}
\text { a: } \mathrm{R}=\mathrm{Ph} \\
\text { b: } \mathrm{R}=4-\mathrm{CIC}_{6} \mathrm{H}_{4} \\
\text { c: } \mathrm{R}=4-\mathrm{MeOC}_{6} \mathrm{H}_{4} \\
\text { d: } \mathrm{R}=2-\text {-naphthyl } \\
\text { e: } \mathrm{R}=\mathrm{PhCH}_{2} \mathrm{CH}_{2} \\
\text { f: } \mathrm{R}=\mathrm{Me}_{2} \mathrm{CHCH}_{2} \\
\text { g: } \mathrm{R}=c-\mathrm{C}_{6} \mathrm{H}_{11}
\end{array}\right]
$$

\begin{tabular}{|c|c|c|c|c|c|c|}
\hline \multirow[b]{2}{*}{ Entry } & \multirow[b]{2}{*}{ Substrate } & \multicolumn{2}{|c|}{$\mathrm{R}_{2}{ }_{2} \mathrm{Zn}$} & \multicolumn{3}{|c|}{ Product } \\
\hline & & $\mathrm{R}^{\prime}$ & Equiv & No. & Yield $^{\mathrm{b}}(\%)$ & $e^{c}(\%)$ \\
\hline 1 & $2 a$ & $\mathrm{Et}$ & 6 & Заa & 83 & 80 \\
\hline $2^{d}$ & $2 a$ & Et & 6 & Заa & 95 & 62 \\
\hline 3 & $4 a$ & $\mathrm{Et}$ & 6 & Заа & 86 & 84 \\
\hline 4 & $2 a$ & $i-\operatorname{Pr}$ & 6 & 3ab & 77 & 76 \\
\hline 5 & $4 a$ & $i-\operatorname{Pr}$ & 6 & 3ab & 88 & 64 \\
\hline 6 & $2 a$ & $n-\mathrm{Bu}$ & 6 & Зас & 80 & 86 \\
\hline 7 & $4 a$ & $n-\mathrm{Bu}$ & 6 & Зас & 82 & 64 \\
\hline 8 & $4 b$ & $\mathrm{Et}$ & 6 & $3 \mathbf{b}$ & 99 & 78 \\
\hline 9 & $4 c$ & Et & 6 & $3 c$ & 61 & 88 \\
\hline 10 & 4d & Et & 6 & 3d & 84 & 74 \\
\hline 11 & $4 e$ & $\mathrm{Et}$ & 8 & $3 \mathbf{e}$ & 82 & 30 \\
\hline 12 & $4 f$ & $\mathrm{Et}$ & 6 & $3 f$ & 92 & 32 \\
\hline 13 & $4 g$ & Et & 6 & $3 g$ & 80 & 56 \\
\hline
\end{tabular}

Scheme 3. Reagents and conditions: (i) polymeric ligand 1a (1 equiv), toluene, $25{ }^{\circ} \mathrm{C}, 2$ days; (ii) Separation; (iii) $\mathrm{NH}_{4} \mathrm{Cl}$ (aq.).

Table 4. Enantioselective addition of dialkylzinc reagents to in situ generated $N$-(diphenylphosphinyl)imines $\mathbf{2}$ in the presence of polymeric ligand $\mathbf{1 a}$. Preparation of compounds $3^{\mathrm{a}}$

a All reactions were performed by dropwise addition of diethylzinc (6 equiv) over ca. $10 \mathrm{~min}$ to a stirred suspension of the polymeric ligand 1a (1 equiv) and the substrate 2 or $4(0.25$ $\mathrm{mmol})$ in anhydrous toluene $(3.5 \mathrm{~mL})$ under argon at room temperature and stirring was continued for 2 days.

${ }^{\mathrm{b}}$ Isolated yield after column chromatography (silica gel, hexane/ethyl acetate) based on the substrate 2 or 4 . All isolated compounds 3 were $\geq 95 \%$ pure $\left(300 \mathrm{MHz}{ }^{1} \mathrm{H} \mathrm{NMR}\right)$.

${ }^{c}$ Enantiomeric excess determined by HPLC using a ChiralCel OD-H column or a Chiralpak AD column. The $(R)$-enantiomer was the major one in all cases.

${ }^{\mathrm{d}}$ Reaction performed under microwave irradiation at $50{ }^{\circ} \mathrm{C}(70 \mathrm{~W}, 0.8$ bar $)$ for $1 \mathrm{~h}$. 
Next, the addition of diethylzinc to several aromatic and aliphatic imines $\mathbf{2 b}-\mathbf{g}$ was attempted. Unfortunately, when we tried to prepare those imines by literature procedures, ${ }^{18}$ we obtained them in very small amounts and we could not purify them neither by column chromatography on deactivated silica gel nor by recrystallization. Fortunately, imines $\mathbf{2 b}-\mathbf{g}$ could be generated in situ from their corresponding sulfinic acid adducts $\mathbf{4 b}-\mathbf{g}$ (Scheme 3). All imines derived from aromatic aldehydes gave very good ee's irrespective of the electronic nature of the substituents on the aromatic ring (Table 4, entries 8-10). It is worth noting that the addition of dibutylzinc to benzaldimine $\mathbf{2 a}$ and the reaction of diethylzinc with adduct $\mathbf{4 c}$, having a methoxy group at the para position of the benzene ring, afforded products 3ac $(86 \%$ ee) and 3c $(88 \%$ ee), respectively, with ee values that are very similar to the ones obtained when $N$-benzyl-L-prolinol was used as an homogeneous ligand to catalyse the same reactions ( 90 and $92 \%$ ee, respectively). ${ }^{13 \mathrm{~b}}$ For the rest of the examples of additions to aromatic imines (Table 4, entries 3, 4, 8 and 10), an average loss of ee of $13 \%$ was observed in comparison with the reactions catalysed by the homogeneous ligand. Unfortunately, the polymeric ligand 1a was less efficient to promote the enantioselective addition of diethylzinc to the in situ generated aliphatic imines 2e-g: although the isolated yields were very good in all cases, only moderate ee values were observed in the addition products 3e-g (30-56\%, Table 4, entries 11-13).

As described above, ligand 1a has shown to be an efficient and recyclable catalyst for the addition of dialkylzinc reagents to $N$-(diphenylphosphinyl)aldimines. Since the phosphinyl group can be easily removed from the addition products under acidic conditions, ${ }^{3}$ this methodology represents an interesting procedure to synthesize $\alpha$-branched primary amines with high optical purities. It is worth noting that D-prolinol is also commercially available and could be used to prepare another polymeric ligand with enantiomeric aminoalcohol moieties, which would provide the opportunity of preparing the enantiomers of the final amine products.

\section{Conclusions}

In conclusion, we have reported that $N$-benzyl-L-prolinol anchored to a polymeric support is an efficient promoter for the addition of dialkylzinc reagents to $N$-(diphenylphosphinyl)imines. By proper choice of the prolinol content, a polymeric ligand was prepared that could be recovered and used in up to five consecutive cycles without significant loss of enantioselectivity. The enantiomeric excesses achieved with the supported catalyst were slightly lower than the ones obtained with $N$-benzyl-L-prolinol as an homogeneous ligand, but the former presents the advantage of its recyclability. This methodology is very useful for the preparation of enantiomerically enriched protected amines from aromatic $N$-(diphenylphosphinyl)imines, being less effective when imines bearing aliphatic substituents were used as substrates.

\section{Experimental}

\subsection{General}

For general experimental information, see reference 11. Imine 2a was prepared according to a literature procedure. $^{9 \mathrm{~h}, 18}$ Adducts 4 were prepared by reaction of the corresponding aldehydes with $P, P$ diphenylphosphinic amide and $p$-toluenesulfinic acid following a literature procedure. ${ }^{17}$ Commercially available L-prolinol (Aldrich, 97\%), Merrifield resins (Aldrich, $1 \mathrm{mmol} \mathrm{Cl} / \mathrm{g}$; Aldrich, $1.5 \mathrm{mmol} \mathrm{Cl} / \mathrm{g}$; Fluka, $1.7 \mathrm{mmol} \mathrm{Cl} / \mathrm{g}$; Aldrich, $4.3 \mathrm{mmol} \mathrm{Cl} / \mathrm{g}$ ), Wang-type resin (Aldrich, 0.5-1.5 mmol Br/g), solutions of $\mathrm{Et}_{2} \mathrm{Zn}$ (Aldrich, $1.0 \mathrm{M}$ in hexanes), $(\mathrm{i}-\mathrm{Pr})_{2} \mathrm{Zn}$ (Aldrich, $1.0 \mathrm{M}$ in toluene) and $(n-\mathrm{Bu})_{2} \mathrm{Zn}$ (Acros, $1.0 \mathrm{M}$ in heptane) were used as received. Anhydrous toluene (Scharlau, 99.9\%, $\mathrm{H}_{2} \mathrm{O} \leq 0.017 \%$ ) was used as solvent in all the addition reactions. HPLC analyses were performed at $25^{\circ} \mathrm{C}$ on a JASCO apparatus, equipped with a PU-2089 Plus pump, a MD-2010 Plus detector and an AS-2059 Plus automatic injector. Elemental analyses were performed by the Technical Services of the University of Alicante

\subsection{Preparation of the polymeric ligands 1 . General procedure}


L-prolinol $(1.0 \mathrm{~mL}, 10.5 \mathrm{mmol})$ was added to a suspension of the Merrifield or Wang-type resin $(2.5 \mathrm{mmol}$ of $\mathrm{Cl})$ in DMF $(25 \mathrm{~mL})$ and the mixture was stirred for $90 \mathrm{~h}$ at room temperature. The solid was filtered and successively washed with DMF, EtOH, THF, THF: $\mathrm{H}_{2} \mathrm{O}(1: 1), \mathrm{MeOH}$, acetone and $\mathrm{Et}_{2} \mathrm{O}$, being then dried under vacuum for several hours until no loss of weight was observed. The number of mmol of prolinol per gram of the polymeric ligand was calculated by determining the nitrogen content of the polymer by elemental analysis, giving the following results: 1 a $(0.86 \% \mathrm{~N}, 0.61 \mathrm{mmol}$ prolinol $/ \mathrm{g}), \mathbf{1 b}(1.22 \% \mathrm{~N}, 0.87 \mathrm{mmol} \mathrm{prolinol} / \mathrm{g}), \mathbf{1 c}$ $(1.30 \% \mathrm{~N}, 0.93 \mathrm{mmol}$ prolinol $/ \mathrm{g}), \mathbf{1 d}(1.52 \% \mathrm{~N}, 1.09 \mathrm{mmol} \mathrm{prolinol} / \mathrm{g}), \mathbf{1 e}(2.08 \% \mathrm{~N}, 1.48 \mathrm{mmol} \mathrm{prolinol} / \mathrm{g})$, 1f $(4.33 \% \mathrm{~N}, 3.10 \mathrm{mmol}$ prolinol $/ \mathrm{g})$ and $\mathbf{1 g}(1.42 \% \mathrm{~N}, 1.00 \mathrm{mmol}$ prolinol $/ \mathrm{g})$.

\subsection{Recyclability study performed with polymeric ligands $1 \mathrm{a}$ and $1 \mathrm{~b}$}

A suspension of imine $2 \mathbf{a}(0.25 \mathrm{mmol})$ and ligand $\mathbf{1 a}$ or $\mathbf{1 b}(0.25 \mathrm{mmol}$ of $\mathrm{N})$ in anhydrous toluene $(3.5 \mathrm{~mL})$ under argon was prepared in a centrifuge tube. Diethylzinc $(1.5 \mathrm{mmol}, 1.5 \mathrm{~mL}$ of a $1.0 \mathrm{M}$ solution in hexanes) was added dropwise over ca. $10 \mathrm{~min}$ to that stirred suspension at room temperature. After stirring for two days at the same temperature, the tube was centrifuged and the liquid layer was carefully extracted with a syringe trying to avoid the extraction of solid particles. Then, anhydrous toluene $(3.0 \mathrm{~mL})$ was added to the solid, the mixture was stirred for $5 \mathrm{~min}$, the tube was again centrifuged and the liquid phase was extracted with a syringe. This washing process was performed three times. The combined organic layers were hydrolysed with an aqueous saturated solution of $\mathrm{NH}_{4} \mathrm{Cl}(10 \mathrm{~mL})$ and work-up was performed as described below (section 4.4).

Solid imine $\mathbf{2 a}(0.25 \mathrm{mmol})$ was quickly added to the centrifuge tube containing the polymeric ligand $\mathbf{1 a}$ or $\mathbf{1 b}$ from the previous reaction and an inert atmosphere was created inside the tube by doing several vacuum-argon cycles. Anhydrous toluene $(3.5 \mathrm{~mL})$ was added to the solid mixture and then diethylzinc $(1.5 \mathrm{mmol}, 1.5 \mathrm{~mL}$ of a 1.0 $\mathrm{M}$ solution in hexanes) was added dropwise over ca. $10 \mathrm{~min}$ to the stirred resulting suspension at room temperature and the reaction was stirred for two days at the same temperature. Following this procedure, ligands 1a and 1b were used in 9 and 6 consecutive reactions, respectively.

\subsection{Addition of dialkylzinc reagents to imines 2 catalysed by ligand 1a. Preparation of compounds 3. General procedure}

The dialkylzinc reagent $(1.5 \mathrm{mmol})$ was added dropwise over ca. $10 \mathrm{~min}$ to a stirred suspension of imine $2 \mathbf{a}$ or adduct $4(0.25 \mathrm{mmol})$ and ligand $1 \mathrm{a}(0.25 \mathrm{mmol}$ of $\mathrm{N})$ in anhydrous toluene $(3.5 \mathrm{~mL})$ under argon at room temperature. After stirring for two days, the polymer was allowed to settle at the bottom of the flask and the liquid layer was carefully extracted with a syringe trying to avoid the extraction of solid particles (if necessary, the mixture was centrifuged before removing the liquid phase). Then, anhydrous toluene $(3.0 \mathrm{~mL})$ was added to the solid, the mixture was stirred for $5 \mathrm{~min}$, the polymer was again allowed to settle and the liquid phase was extracted with a syringe. This washing process was performed three times. The combined organic layers were hydrolysed with an aqueous saturated solution of $\mathrm{NH}_{4} \mathrm{Cl}(10 \mathrm{~mL})$. Water $(5 \mathrm{~mL})$ was added and the mixture was extracted with ethyl acetate $(3 \times 20 \mathrm{~mL})$. The combined organic layers were washed with brine $(10 \mathrm{~mL})$, and then dried $\left(\mathrm{MgSO}_{4}\right)$. After filtration and evaporation of the solvents, the crude residue was purified by column chromatography (silica gel, hexane/ethyl acetate), to give products 3 in the yields and enantiomeric excesses indicated in Table 4. Compounds 3aa, ${ }^{3} \mathbf{3 a b},{ }^{13 \mathrm{~b}}{ }^{3 \mathbf{a c}},{ }^{11} \mathbf{3 b},{ }^{3} \mathbf{3 c}^{6},{ }^{6 \mathrm{k}} \mathbf{3 d},{ }^{13 \mathbf{b}} \mathbf{3 e},{ }^{17} \mathbf{3 f}^{17}$ and $3 \mathbf{g}^{17}$ were characterised by comparison of their physical and spectroscopic data with the ones reported in the literature. These products were analyzed by HPLC on a ChiralCel OD-H column using a $254 \mathrm{~nm}$ UV detector, $10 \% i-$ $\mathrm{PrOH}$ in hexane as eluent and a flow rate of $1.0 \mathrm{~mL} / \mathrm{min}$ or on a Chiralpak AD column using a $254 \mathrm{~nm}$ UV detector, $20 \% \mathrm{i}-\mathrm{PrOH}$ in hexane as eluent and a flow rate of $1.0 \mathrm{~mL} / \mathrm{min}$. The retention times were: $8.6(R)$ and $12.3(S)$ for 3aa (OD-H column), $8.6(R)$ and $10.3(S)$ for 3ab (OD-H column), $6.8(R)$ and $12.8(S)$ for 3ac (OD-H column), $11.9(R)$ and $14.1(S)$ for $3 \mathbf{b}($ AD column), $12.9(R)$ and $16.0(S)$ for 3c (AD column), $10.4(R)$ and $14.7(S)$ for 3d (AD column), $22.0(R)$ and $30.7(S)$ for 3e (AD column), $7.5(S)$ and $10.7(R)$ for 3f (AD column), $7.1(S)$ and $8.9(R)$ for $3 g$ (AD column). The absolute configuration of the major enantiomer of 3aa was determined by its hydrolysis ${ }^{3}$ and comparison of the specific rotation of the free amine obtained with the reported data. $^{3}$ The absolute configuration of the major enantiomer of 3ab-ac was tentatively assigned according to the order of elution of the two enantiomers in the HPLC analysis on the analogy of product 3aa. 
For addition products $\mathbf{3 b}$-d, the absolute configuration of the major enantiomer was tentatively assigned according to the HPLC data described in the literature for similar compounds under the same conditions. ${ }^{17}$ The retention times of the two enantiomers of compounds 3e-g have already been described. ${ }^{17}$

\section{Acknowledgements}

This work was generously supported by the Spanish Ministerio de Ciencia e Innovación (MICINN; grant no. CONSOLIDER INGENIO 2010, CSD2007-00006, CTQ2007-65218 and CTQ11-24151) and the Generalitat Valenciana (PROMETEO/2009/039, FEDER and GV/2007/036). R. A. thanks the Spanish Ministerio de Educación y Ciencia for a predoctoral fellowship. J. F. C. thanks the Instituto de Síntesis Orgánica for a fellowship. We also thank MEDALCHEMY S.L. for a gift of chemicals.

\section{References and notes}

1. For reviews on the asymmetric nucleophilic addition to imines, see: (a) Enders, D.; Reinhold, U. Tetrahedron: Asymmetry 1997, 8, 1895-1946; (b) Kobayashi, S.; Ishitani, H. Chem. Rev. 1999, 99, 1069-1094; (c) Charette, A. B.; Boezio, A. A.; Côté, A.; Moreau, E.; Pytkowicz, J.; Desrosiers, J.-N.; Legault, C. Pure Appl. Chem. 2005, 77, 1259-1267; (d) Vilaivan, T.; Bhanthumnavin, W.; Sritana-Anant, Y. Curr. Org. Chem. 2005, 9, 1315-1392; (e) Kobayashi, S.; Mori, Y.; Fossey, J. S.; Salter, M. M. Chem. Rev. 2011, 111, 2626-2704.

2. For a review on the use of $N$-phosphinylimines in stereoselective synthesis, see: Weinreb, S. M.; Orr, R. K. Synthesis 2005, 1205-1227.

3. See, for instance: Andersson, P. G.; Guijarro, D.; Tanner, D. J. Org. Chem. 1997, 62, 7364-7375.

4. (a) Knochel, P. In Comprehensive Organic Synthesis; Trost, B. M., Fleming, I., Shreiber, S. L., Eds.; Pergamon Press: Oxford, 1991; Vol. 1; chapter 1.7; (b) Erdik, E. Organozinc Reagents in Organic Synthesis; CRC Press: Boca Raton, 1996.

5. (a) Rozema, M. J.; Sidduri, A.; Knochel, P. J. Org. Chem. 1992, 57, 1956-1958; (b) For a review, see: Knochel, P.; Singer, R. D. Chem. Rev. 1993, 93, 2117-2188; (c) Knochel, P. Synlett 1995, 393-403; (d) Vettel, S.; Vaupel, A.; Knochel, P. Tetrahedron Lett. 1995, 36, 1023-1026; (e) Vettel, S.; Vaupel, A.; Knochel, P. J. Org. Chem. 1996, 61, 7473-7481; (f) Langer, F.; Schwink, L.; Devasagayaraj, A.; Chavant, P.-Y.; Knochel, P. J. Org. Chem. 1996, 61, 8229-8243; (g) Micouin, L.; Knochel, P. Synlett 1997, 327-328; (h) Boudier, A.; Bromm, L. O.; Lotz, M.; Knochel, P. Angew. Chem. Int. Ed. 2000, 39, 4415-4435; (i) Knochel, P.; Leuser, H.; Gong, L.-Z.; Perrone, S.; Kneisel, F. F. In The Chemistry of Organozinc Compounds; Rappoport, Z., Marek, I., Eds.; John Wiley \& Sons Ltd.: Chichester, 2007; pp. 287-393; (j) Knochel, P.; Schade, M. A.; Bernhardt, S.; Manolikakes, G.; Metzger, A.; Piller, F. M.; Rohbogner, C. J.; Mosrin, M. Beilstein J. Org. Chem. 2011, 7, 1261-1277.

6. Examples of the use of $\beta$-aminoalcohols as additives: (a) Soai, K.; Hatanaka, T.; Miyazawa, T. J. Chem. Soc., Chem. Commun. 1992, 1097-1098; (b) Suzuki, T.; Narisada, N.; Shibata, T.; Soai, K. Tetrahedron: Asymmetry 1996, 7, 2519-2522; (c) Reference 3; (d) Guijarro, D.; Pinho, P.; Andersson, P. G. J. Org. Chem. 1998, 63, 2530-2535; (e) Jimeno, C.; Vidal-Ferran, A.; Moyano, A.; Pericàs, M. A.; Riera, A. Tetrahedron Lett. 1999, 40, 777-780; (f) Brandt, P.; Hedberg, C.; Lawonn, K.; Pinho, P.; Andersson, P. G. Chem. Eur. J. 1999, 5, 1692-1699; (g) Jimeno, C.; Reddy, K. S.; Solà, L.; Moyano, A.; Pericàs, M. A.; Riera, A. Org. Lett. 2000, 2, 3157-3159; (h) Pinho, P.; Andersson, P. G. Tetrahedron 2001, 57, 1615-1618; (i) Zhang, H.-L.; Zhang, X.-M.; Gong, L.-Z.; Mi, A.-Q.; Cui, X.; Jiang, Y.-Z.; Choi, M. C. K.; Chan, A. S. C. Org. Lett. 2002, 4, 1399-1402; (j) Beresford, K. J. M. Tetrahedron Lett. 2002, 43, 7175-7177; (k) Zhang, H.-L.; Jiang, F.; Zhang, X.-M.; Cui, X.; Gong, L.-Z.; Mi, A.-Q.; Jiang, Y.-Z.; Wu, Y.-D. Chem. Eur. J. 2004, 10, 1481-1492; (1) Beresford, K. J. M. Tetrahedron Lett. 2004, 45, 6041-6044; (m) Xu, X.-H.; Qiu, X.-L.; Qing, F.-L. Tetrahedron 2008, 64, 7353-7361.

7. For the use of iminoalcohols as additives, see reference $6 \mathrm{k}$.

8. Use of hydroxyoxazolines as additives: (a) Zhang, X.; Lin, W.; Gong, L.; Mi, A.; Cui, X.; Jiang, Y.; Choi, M. C. K.; Chan, A. S. C. Tetrahedron Lett. 2002, 43, 1535-1537; (b) Zhang, X.-M.; Zhang, H.-L.; Lin, W.-Q.; Gong, L.-Z.; Mi, A.-Q.; Cui, X.; Jiang, Y.-Z.; Yu, K.-B. J. Org. Chem. 2003, 68, 4322-4329; (c) Yan, G.; Wu, Y.; Lin, W.; Zhang, X. Tetrahedron: Asymmetry 2007, 18, 2643-2648. 
9. Use of copper catalysts: (a) Shi, M.; Wang, C.-J. Adv. Synth. Catal. 2003, 345, 971-973; (b) Boezio, A. A.; Charette, A. B. J. Am. Chem. Soc. 2003, 125, 1692-1693; (c) Boezio, A. A.; Pytkowicz, J.; Côté, A.; Charette, A. B. J. Am. Chem. Soc. 2003, 125, 14260-14261; (d) Côté, A.; Boezio, A. A.; Charette, A. B. Angew. Chem. Int. Ed. 2004, 43, 6525-6528; (e) Wang, M.-C.; Liu, L.-T.; Hua, Y.-Z.; Zhang, J.-S.; Shi, Y.-Y.; Wang, D.-K. Tetrahedron: Asymmetry 2005, 16, 2531-2534; (f) Kim, B.-S.; Kang, S.-W.; Kim, K. H.; Ko, D.-H.; Chung, Y.; Ha, D.-C. Bull. Korean Chem. Soc. 2005, 26, 1501-1502; (g) Côté, A.; Charette, A. B. J. Org. Chem. 2005, 70, 10864-10867; (h) Desrosiers, J.-N.; Côté, A.; Boezio, A. A.; Charette, A. B.; Denmark, S. E.; Montgomery, J. I. Org. Synth. 2006, 83, 5-17; (i) Lauzon, C.; Charette, A. B. Org. Lett. 2006, 8, 2743-2745; (j) Shi, M.; Lei, Z.-Y.; Xu, Q. Adv. Synth. Catal. 2006, 348, 2237-2242; (k) Wang, M.-C.; Xu, C.-L.; Cheng, F.; Ding, X. Tetrahedron 2006, 62, 12220-12226; (1) Chen, J.; Li, D.; Ma, H.; Cun, L.; Zhu, J.; Deng, J.; Liao, J. Tetrahedron Lett. 2008, 49, 6921-6923; (m) Bonnaventure, I.; Charette, A. B. Tetrahedron 2009, 65, 4968-4976.

10. Use of zirconium catalysts: (a) Porter, J. R.; Traverse, J. F.; Hoveyda, A. H.; Snapper, M. L. J. Am. Chem. Soc. 2001, 123, 984-985; (b) Porter, J. R.; Traverse, J. F.; Hoveyda, A. H.; Snapper, M. L. J. Am. Chem. Soc. 2001, 123, 10409-10410.

11. Use of a nickel catalyst: Almansa, R.; Guijarro, D.; Yus, M. Tetrahedron 2007, 63, 1167-1174.

12. Use of a rhodium catalyst: Crampton, R. H.; El, H. S.; Fox, M. E.; Woodward, S. Tetrahedron: Asymmetry 2009, 20, 2497-2503.

13. (a) Almansa, R.; Guijarro, D.; Yus, M. Tetrahedron: Asymmetry 2007, 18, 896-899; (b) Almansa, R.; Guijarro, D.; Yus, M. Tetrahedron: Asymmetry 2007, 18, 2828-2840; (c) Almansa, R.; Guijarro, D.; Yus, M. Tetrahedron: Asymmetry 2008, 19, 1376-1380.

14. For reviews on the use of supported catalysts in asymmetric synthesis, including the addition of dialkylzinc reagents to aldehydes, see: (a) Clapham, B.; Reger, T. S.; Janda, K. D. Tetrahedron 2001, 57, 4637-4662; (b) McNamara, C. A.; Dixon, M. J.; Bradley, M. Chem. Rev. 2002, 102, 3275-3299; (c) Fan, Q.-H.; Li, Y.M.; Chan, A. S. C. Chem. Rev. 2002, 102, 3385-3466; (d) Trindade, A. F.; Gois, P. M. P.; Afonso, C. A. M. Chem. Rev. 2009, 109, 418-514; (e) Somanathan, R.; Flores-Lopez, L. Z.; Montalvo-Gonzalez, R.; Chavez, D.; Parra-Hake, M.; Aguirre, G. Mini-Rev. Org. Chem. 2010, 7, 10-22.

15. (a) Soai, K.; Suzuki, T.; Shono, T. J. Chem. Soc., Chem. Commun. 1994, 317-318; (b) Suzuki, T.; Shibata, T.; Soai, K. J. Chem. Soc., Perkin Trans. 1 1997, 2757-2760; (c) Suzuki, T.; Hirokawa, Y.; Ohtake, K.; Shibata, T.; Soai, K. Tetrahedron: Asymmetry 1997, 8, 4033-4040; (d) Suzuki, T.; Narisada, N.; Shibata, T.; Soai, K. Polym. Advan. Technol. 1999, 10, 30-38; (e) Sato, I.; Kodaka, R.; Shibata, T.; Hirokawa, Y.; Shirai, N.; Ohtake, K.; Soai, K. Tetrahedron: Asymmetry 2000, 11, 2271-2275; (f) Sato, I.; Hosoi, K.; Kodaka, R.; Soai, K. Eur. J. Org. Chem. 2002, 3115-3118; (g) Soai, K.; Sato, I. C. R. Chim. 2003, 6, 1097-1104.

16. The microwave-accelerated enantioselective addition of dialkylzinc reagents to N(diphenylphosphinyl)imines catalysed by ligands with the prolinol framework has been reported by us. See reference $13 \mathrm{c}$.

17. Côté, A.; Boezio, A. A.; Charette, A. B. Proc. Natl. Acad. Sci. USA 2004, 101, 5405-5410.

18. (a) Krzyzanowska, B.; Stec, W. J. Synthesis 1982, 270-273; (b) Jennings, W. B.; Lovely, C. J. Tetrahedron 1991, 47, 5561-5568. 